\title{
Pelaksanaan Teknik Evaluasi Pembelajaran Sejarah Peradaban Islam di IAIN Sultan Maulana Hasanuddin Banten
}

\author{
Ratni \\ Universitas Islam Negeri Sultan Maulana Hasanuddin Banten \\ ratniway@gmail.com
}

\begin{abstract}
The purpose of the research is to describing technique evalution for learning Islamic Civilization History. The research focus knowing what kind of evaluation are use by lecturer and why they choose for the evaluation. The content of this research is expected to be a resource for history learning among the lecturer. The research is conducted at IAIN Sultan Maulana Hasanuddin Banten in Faculty of Tarbiyah and Adab, Faculty of Syariah and Economic Islam and Faculty of Ushuluddin and Da'wah. The research method is qualitative Method. The research was conducted through observation, interview, and documens. The research has found that the result are factors influencing lecturer Islamic Civilization History to choose and use evaluation technic are two. It's the learning purpose and lecturer education background. The combination between two factors have produce a pattern for chooshing and implementation for evaluation technique to learn Islamic Civilization History.
\end{abstract}

Keywords: Evaluation Teknique, Islamic Civilization History, Lecturer

\begin{abstract}
Abstrak: Tujuan dari penelitian ini untuk memberikan gambaran pelaksanaan teknik evaluasi pembelajaran Sejarah Peradaban Islam. Fokus penelitian ini adalah untuk mengetahui bagaimana teknik evaluasi yang digunakan dosen dan mengapa mereka memilih teknik tertentu. Kajian penelitian ini diharapkan dapat menjadi bahan kajian dalam pembelajaran sejarah oleh para dosen. Penelitian dilakukan di Institut Agama Islam Negeri (IAIN) Sultan Maulana Hasanuddin Banten di Fakultas Tarbiyah dan Adab, fakultas Syariah dan Ekonomi Islam, dan Fakultas Ushuluddin dan Dakwah. Metode Penelitiannya adalah penelitian kualitatif. Pengambilan data dilakukan melalui dokumen, observasi, dan wawancara. Temuan penelitian ini mendapatkan hasil bahwa faktor-faktor yang mempengaruhi dosen mata kuliah Sejarah Peradaban Islam memilih dan menggunakan teknik evaluasi ada dua, yaitu : tujuan pembelajaran dan latar belakang pendidikan dosen. Gabungan dari dua faktor temuan itu menghasilkan pola pemilihan dan pelaksanaan teknik evaluasi pembelajaran Sejarah Peradaban Islam.
\end{abstract}

Kata kunci: Dosen, Sejarah Peradaban Islam, Teknik Evaluasi.

\section{PENDAHULUAN}

Pembelajaran sejarah adalah pembelajaran yang komprehensif antara daya pikir imajinasi dan daya kritis terhadap fakta serta mampu 
bersikap yang diaplikasikan dalam nilai-nilai kehidupan dari peristiwa sejarah (Phenix: 1964, 239-240). Pada dasarnya sejarah menawarkan bagaimana cara belajar untuk berpikir dan bersikap. Sejarah bukan untuk menghapal sebagaimana opini yang telah berkembang di masyarakat (Supriatna: 2012, 124).

Pembelajaran sejarah bertujuan membangun karakter pembelajar dengan menciptakan kebangkitan kesadaran empati (Aman: 2011, 2) Pembelajaran sejarah membangun pendidikan karakter dengan menanamkan nilai-nilai kearifan bangsa dan peradaban. Melalui pembelajaran sejarah, akan terbentuk manusia yang bermartabat dalam berbangsa (Hasan: 2012). Manusia yang memiliki kesadaran sejarah adalah manusia yang berdasarkan kemampuan kognitif mampu merespon menjadi afektif.

Sejarah Peradaban Islam merupakan perwujudan manusia yang dengan kekuatan akidah dan moralnya menjadi faktor penentu dalam perubahan perkembangan sejarah Islam (Badri Yatim: 2006, 2). Sejarah Peradaban Islam adalah pembelajaran yang membahas perkembangan sejarah umat Islam dalam bidang politik, ekonomi dan teknologi pada periode klasik, pertengahan dan modern yang bertujuan menghasilkan intelektual muda yang kritis dan memiliki kepribadian Islam.

Sejarah Peradaban Islam (SPI) diajarkan oleh dosen di Perguruan Tinggi Islam. Dosen yang mengajarkan SPI dianggap menguasai pembelajarannya. Selain merancang pembelajaran dan penguasaan materi, salah satu kemampuan dosen adalah mampu menetapkan teknik evaluasi. Hal ini menjadi indikator penting dalam pembelajaran. Tanpa kemampuan menetapkan teknik evaluasi yang tepat dan efektif sebagai 
bagian dari unsur tersebut, dosen dianggap tidak kompeten dalam bidangnya.

Evaluasi dalam pembelajaran Sejarah Peradaban Islam merupakan proses berkelanjutan (Gronlund: 1976, 6). Evaluasi digunakan untuk mendapatkan informasi akurat pada tingkat pencapaian tujuan instruksional dalam ranah kognitif, afektif dan psikomotorik (Bloom: 1979, 7). Untuk mendapatkan informasi tersebut diperlukan suatu data yang diperoleh melalui pengukuran dan penilaian. Evaluasi juga merupakan penentuan nilai untuk memperoleh informasi yang digunakan untuk pemanfaatan penentuan nilai suatu program, produk, prosedur, atau objek pemanfaatan potensial. Pendekatan-pendekatan alternatif yang disusun untuk memperoleh atau mencapai tujuan tertentu.

Teknik Evaluasi Pembelajaran Sejarah Peradaban Peradaban Islam (SPI) adalah pelaksanaan evaluasi yang berorientasi proses dari tujuan perencanaan, pengalaman pelaksanaan pembelajaran, dan teknik evaluasi tes maupun non tes untuk mengetahui, mengukur dan menilai pembelajaran SPI yang kompleks dari mahasiswa yang bertujuan menghasilkan daya pikir imajinasi, daya kritis dan sikap kepribadian Islam melalui teknik evaluasi yang tepat dan efektif.

Dosen SPI seharusnya memiliki kejelasan dalam evaluasi pembelajaran. Menetapkan teknik evaluasi menjadi indikator penting dalam pembelajaran SPI. Tanpa kemampuan menetapkan teknik evaluasi yang tepat dan efektif, dosen dianggap tidak kompeten dalam bidangnya. Berdasarkan permasalahan-permasalahan di atas, maka penelitian ini penting untuk menggambarkan bagaimana pelaksanaan teknik evaluasi 
dosen pada pembelajaran Sejarah Peradaban Islam, khususnya di IAIN Sultan Maulana Hasanuddin Banten.

\section{METODE}

Penelitian ini dilaksanakan di IAIN Sultan Maulana Hasanuddin Banten. Metode penelitian yang digunakan adalah metode kualitatif. Teknik pengumpulan datanya melalui dokumen, observasi, dan wawancara mendalam pada tujuh orang dosen sebagai informan inti, yang ditentukan melalui prosedur purposive sampling. Digunakan analisis model interaktif untuk menganalisa unsur analisis (reduksi, sajian data, dan penarikan kesimpulan) saling berinteraksi. Dalam penelitian ini dilakukan melalui empat cara, yaitu: triangulasi, member checking, peningkatan ketekunan, dan perpanjangan keikutsertaan.

\section{HASIL}

Berdasarkan hasil dokumen, observasi dan wawancara diperoleh bahwa tujuh orang dosen Sejarah Peradaban Islam (SPI) di Institut Agama Islam Negeri (IAIN) Sultan Maulana Hasanuddin Banten yang tersebar di berbagai Fakultas memiliki karakateristik yang berbeda berdasarkan pada faktor-faktor sebagai berikut:

\section{Latar Belakang Pendidikan}

Latar belakang pendidikan dosen Sejarah Peradaban Islam yang sesuai dengan jurusan dan bidangnya hanyalah dosen yang mengajar di Fakultas Tarbiyah dan Adab. Adapun Fakultas Syariah \& Ekonomi dan Fakultas Ushuludin \& Dakwah. Dari latar belakang pendidikan, empat dosennya tidak sesuai dengan mata kuliah tersebut. Pendidikan dosen Sejarah Peradaban Islam di Fakultas Ushuludin adalah Jurusan Metode 
Studi Islam biasa mengajar mata kuliah Tafsir Hadist, sedangkan dosen Sejarah Peradaban Islam di Fakultas Syariah adalah dosen ilmu Kalam. Maka dosen dikelompokkan empat kategori berdasarkan pada latar belakang pendidikannya.

Kategori pertama adalah yang latar belakang pendidikannya dari jurusan sejarah dan pendidikan. Ibu Sita masuk ke dalam kategori pertama. Kategori kedua merupakan kategori dosen yang memiliki latar belakang pendidikan dari jurusan sejarah adalah Bapak Zami, Bapak Soni dan ibu Evi. Kategori ketiga adalah dosen yang latar belakang pendidikannya dari Jurusan Sejarah dan pernah punya pengalaman mengajar di sekolah. Dosen dalam kategori ini adalah Bapak Bony. Kategori keempat dosen yang tidak memiliki latar belakang pendidikan Jurusan Sejarah maupun bukan dari Jurusan pendidikan adalah Ibu Oki dan Bapak Upi. Mereka berdua diminta oleh Fakultasnya mengajar Sejarah Peradaban Islam.

\section{Perencanaan Teknik Evaluasi Pembelajaran Sejarah Peradaban Islam}

Berdasarkan hasil penelitian di lapangan pada tujuh orang dosen pengajar Sejarah Peradaban Islam, ditemukan ada 3 kelompok kategori dalam perencanaan pembelajaran. Kategori pertama merupakan dosen yang membuat silabus sebelum perkuliahan dan membahasnya dengan mahasiswa. Bapak Bony, Bapak Upi dan ibu Sita termasuk kategori ini. Kategori kedua merupakan dosen yang membuat silabus dan memberikannya pada mahasiswa di awal perkuliahan tanpa membahasnya. Mereka adalah Bapak Soni, Ibu Evi dan Ibu Oki. Kategori ketiga merupakan dosen yang menyerahkan silabus setelah diminta oleh Fakultas di akhir perkuliahan, tapi tidak memberikannya kepada 
mahasiswa, pada kategori ketiga ini dosen yang termasuk adalah Bapak Zami.

\section{Proses Pembelajaran Sejarah Peradaban Islam}

Proses pembelajaran merupakan penerapan dari tujuan pembelajaran dan pelaksanaan perencanaan pembelajaran. Terdapat tiga kategori dalam masalah variasi teknik evaluasi dan bobot penilaiannya. Kategori pertama, dosen yang memiliki tingkat kesesuaian antara tujuan dengan pelaksanaan pembelajaran. Dosen kategori pertama, yaitu Bapak Bony, Bapak Soni, dan Ibu Sita. Kategori kedua, dosen yang cukup seimbang antara tujuan dengan proses pembelajaran. Dosen kategori kedua, yaitu Bapak Upi, Bapak Sony, dan Ibu Evi. Kategori ketiga, dosen yang tidak sesuai antara tujuan yang direncanakan dengan pelaksanaan pembelajarannya. Dosen kategori ketiga adalah Ibu Oki dan Bapak Zami.

\section{Pelaksanaan Evaluasi Pembelajaran Sejarah Peradaban Islam}

Evaluasi pembelajaran Sejarah Peradaban Islam, dilakukan dengan menggunakan teknik evaluasi berupa tes dan non tes. Dominannya dosen memilih tes sebagai bagian dari mengetahui kemampuan mahasiswanya. Tes digunakan pada waktu Ujian Tengah Semester (UTS) dan Ujian Akhir Semester (UAS). Mayoritas dosen membuat soal essay untuk UTS dan UAS. Teknik evaluasi non tes yang digunakan dosen Sejarah Peradaban Islam adalah makalah, review book, dan laporan observasi. Tugas berupa makalah menekankan pada lima pokok penilaian, tugas terstruktur ini yang dilakukan secara kelompok ditentukan temanya berdasarkan silabus yang digunakan oleh dosen. Tema-tema itu akan dibahas dalam setiap pertemuan dalam awal perkuliahan sampai akhir. Tugas-tugas ini dibuat oleh mahasiswa sebelum mereka melakukan presentasi di dalam kelas. 
Presentasi sendiri berlangsung sesuai dengan jadwal perkuliahan. Mahasiswa hanya membuat dua makalah saja, satu untuk dosen satu untuk kelompok mereka. Mahasiswa tidak menggandakan makalahnya untuk dibagikan pada kelompok-kelompok lain sehingga kelompok lain hanya mendengarkan paparan makalah yang dibacakan oleh kelompok yang presentasi.

Review book digunakan oleh Pak Boni dengan tujuan agar mahaiswa mempersiapkan diri dengan membaca materi yang akan dibahas di kelas. Teknik evaluasi yang digunakan ini Pak Boni, memang disampaikan oleh mahasiswa yang diajarnya. Berdasarkan hasil wawancara Pak Boni diperkuliahannya memberi tugas pada mahasiswa untuk merangkum materi. Mahasiswa diminta untuk menulis dengan tangan di kertas folio bergaris materi di buku acuan Sejarah Peradaban Islam yang ditulis oleh Badri Yatim. Namun mahasiswa yang diajar Pak Boni pada umumnya tidak membaca apa yang mereka buat. Tugas review book dikumpulkan di setiap perkuliahan.

Agar terhindar dari plagiat atau korban copy paste, maka teknik evaluasi oleh pak Upi dengan menugaskan mahasiswa dengan bentuk laporan observasi. Adapun temanya diambil berdasarkan sejarah desa daerah masing-masing, sehingga mendapatkan ide-ide orisinil dan hasil yang murni dari pemikiran mereka. Untuk mendapatkan laporan observasi mereka harus menggali, mengamati, mewawancarai bahkan mengorek-ngorek dokumen di kantor Kelurahan mereka. Wawancara pun dilakukan pada para pemangku atau tokoh aparat maupun orang tua dan tetangga mereka yang sudah sepuh. Keseluruhan dari apa yang mereka dapatkan itu harus mereka uraikan dalam bentuk laporan yang sudah 
ditentukan oleh dosen. Dari latar belakang perumusan masalah pembahasan sampai pada kesimpulan dan saran.

Masih menurut dosen yang sama, bentuk tugas terstruktur ini sangat menantang mahasiswa karena dari tingkat kesulitannya tinggi baik dari segi dana, tenaga dan waktu. Namun hasilnya memuaskan bagi dosen dan bagi mahasiswa, mereka jadi tahu bagaimana sejarah desa mereka dan sadar bahwa dengan adanya sejarah. Jadilah makna sejarah mereka dapatkan pemahamannya bahwa sejarah berkaitan antara masa sekarang dengan masa yang akan datang. Sejarah menjadi learning society yaitu masyarakat pembelajar. Sejarah jadi membumi bahwa sejarah bisa terkait dengan hal-hal di sekeliling kita dan itu bagian hal terpenting bagi hidup kita. Sejarah menjadi pengalaman bermakna bagi orang yang merasakannya.

Dari hasil penelitian yang dilakukan tidak satu dosenpun membuat format penilaian afektif secara khusus untuk mata kuliah Sejarah Peradaban Islam. Penilaian afektif dibuat dengan tanda saja di daftar hadir bagi mahasiswa yang rajin. Dosen lebih memilih dalam ranah kognitif karena dianggap efektif dan efisien. Sudut pandang inilah yang menyebabkan teknik tes lebih digemari dibandingkan teknik non tes.

\section{PEMBAHASAN}

Pelaksanaan teknik evaluasi belajar mata kuliah Sejarah Peradaban Islam oleh dosen di IAIN Sultan Maulana Hasanuddin Banten dipengaruhi oleh beberapa faktor, yaitu: tujuan pembelajaran Sejarah Peradaban Islam dan latar belakang pendidikan dosen. 


\section{Tujuan Pembelajaran Sejarah Peradaban Islam}

Rancangan teknik evaluasi pembelajaran Sejarah Peradaban Islam disesuaikan dengan tujuan pembelajaran yang ingin dituju. Pada umumnya dosen mata kuliah Sejarah Peradaban Islam memahami bahwa pembelajarannya merupakan bagian dari transfer pengetahuan. Menempatkan sejarah sebagai transfer ilmu adalah berorientasi pada materi yang berupa informasi yang detail terhadap fakta maupun data sejarah, sehingga menjadikan para dosen mata kuliah ini mayoritas menekankan teknik evaluasi belajar Sejarah Peradaban Islamnya pada teknik tes tertulis.

Dari hasil penelitian dalam setiap proses pembelajaran diminta mengingat kembali fakta dan data sejarah. Teknik evaluasi, baik membuat makalah, mengerjakan soal-soal UTS dan UAS mahasiswa berkutat pada ranah kognitif dengan level rendah. Minimnya soal ujian yang dibuat dari ranah kognitif dengan level tinggi menurut dosen, karena mahasiswa diberi soal dengan level rendah saja kesulitan.

Untuk teknik evaluasi non tes bagi mereka dalam pembelajaran sejarah bukanlah prioritas utama, karenanya tidak dirancang bentuk khusus untuk teknik evaluasi ini. Begitu pula para dosen tidak membuat format penilaian dalam teknik evaluasi non tes. Mencukupkan pada tes pada ranah kognitif. Sebagaimana yang dikatakan oleh Hutchings bahwa "fundamentally the aim on history teaching depend on philosopy on life" memahami kata Hutching ini bahwa tujuan pembelajaran berasal dari filosofi hidup seseorang. Dominannya teknik evaluasi dengan bentuk tes ini timbul sebagai filosofi hidup yang terekam dalam tujuan belajar di 
silabusnya. Para dosen menyadari pilihan teknik evaluasi adalah konsekuensi dari pilihan tujuan pembelajaran.

Kedua, faktor yang mempengaruhi dosen mata kuliah Sejarah Peradaban Islam dalam melaksanakan teknik evaluasi sejalan dengan apa yang dinyatakan oleh Kochhar dalam bagan gambar tentang segitiga evaluasi. Kocharr menegaskan bahwa pengalaman belajar menjadi sumber dari tujuan belajar dan ini terlaksana penilaiannya dengan memilih teknik evaluasi tertentu. Dari penelitian yang dilakukan pada teknik evaluasi pembelajaran Sejarah Peradaban Islam, dapat dijelaskan bahwa untuk mengetahui bagaimana dalam benak seseorang secara sadar maupun tidak distir oleh pemahamannya yang tersimpan di benak secara rapi.

\section{Latar Belakang Pendidikan Dosen}

Dosen pembelajaran Sejarah Peradaban Islam memiliki latar belakang yang beragam. dua dari tujuh dosen yang diteliti tidak memiliki latar belakang Ilmu Sejarah dan ilmu pendidikan. Adapun lima orang dosen mata kuliah Sejarah Peradaban Islam lainnya memiliki latar belakang ilmu sejarah atau ilmu pendidikan. Teknik evaluasi yang digunakan oleh para dosen mata kuliah Sejarah Peradaban Islam di dapat berdasarkan pengalaman yang berasal saat kuliah di kampusnya dulu. Latar belakang pendidikan menjadi bagian dari pengaruh keputusan dosen dalam pemilihan teknik evaluasi pembelajaran. Di ungkap oleh Sam Wineburg (2006: 209), dkk dalam penelitiannya terhadap para pengajar sejarah.

“Dari pengamatan kami dalam kelas ketika mereka mengajar, jelas bagi kami bahwa latar belakang jurusan yang mereka ambil ketika kuliah membawa pengaruh yang besar dan sering menentukan pada keputusan yang mereka 
ambil tentang pengajaran. Diskusi kami terfokus pada pengaruh latar belakang jurusan ilmu atas pengajaran sejarah Amerika."

Mereka dengan latar pendidikan ilmu sejarah memiliki pemahaman sejarah dari sumber ilmunya, tentunya tidak kesulitan mengajarkan materi Sejarah Peradaban Islam. Pemahaman yang utuh terhadap materi yang detail menjadi bagian dari acuan rancangan pemilihan teknik evaluasi yang mereka buat. Bagi lulusan dari bidang ilmu sejarah kemampuan menguasai data dan menganalisisnya adalah kemampuan terpenting yang perlu dikuasai mahasiswa.

Berbeda dengan dua dosen lain yang berasal dari berbagai latar ilmu sejarah. Salah satu dosen pembelajaran sejarah di Fakultas Ushuluddin merupakan dosen Tafsir Hadist yang menempatkan pembelajaran berdasarkan sudut pandang keilmuannya. Begitu pula satu dosen mata kuliah Sejarah Peradaban Islam dari Fakultas Syariah dan Ekonomi Islam latar belakang pendidikan dosennya dari Jurusan Muamalah. Mereka ini mengungkapkan ketika mengajarkan mata kuliah yang bukan bidangnya, maka konsekuensinya mereka belajar sendiri dari awal untuk mempelajari materi yang akan diajarkan. Namun dalam merancang teknik evaluasinya mereka memiliki beragam pilihan jenis evaluasi.

Salah satu dosen di Fakultas Ushuludin menggunakan life history berupa makalah yang di susun dan ditelitinya dari kelokalan sejarah di desa para mahasiswanya. Menurutnya itu jauh lebih bermakna dan akan mampu menghantarkan kesadaran sejarah atas diri mahasiswa masingmasing. Dari latar belakang pendidikan yang menekankan pada wilayah tafsir, ia mengungkapkan bahwa menetapkan teknik evaluasinya adalah agar mahasiswa mampu menulis untuk menyampaikan pendapatnya sendiri. 
Lain halnya dengan dosen dari Fakultas Syariah dan Ekonomi Islam menetapkan teknik evaluasi setelah berjalannya perkuliahan. Karena menurutnya teknik evaluasi berupa pembuatan peta mampu menghilangkan kebosanan mahasiswa. Selain itu agar mahasiswa dapat menguasai lebih detail letak geografis dan perkembangannya dari setiap Dinasti Peradaban Islam. Dosen ini menugaskan mahasiswa secara berkelompok untuk membuat peta di karton perkembangan wilayah atau geografis dari setiap penguasa Islam dalam setiap periodenya. Teknik evaluasi ini dipilih bukan karena kelebihanya dalam mengoptimalkan kemampuan mahasiswa mencerna pembelajaran dalam ranah psikomotorik, namun lebih karena dapat memotivasi mahasiswanya.

Berdasarkan latar belakang pendidikan para dosen menetapkan teknik evaluasinya. Sebagaimana yang diungkap Sam (2006: 209) dalam bukunya Learning History, menyatakan bahwa:

“... jelas bagi kami bahwa latar belakang jurusan yang mereka ambil ketika kuliah membawa pengaruh yang besar dan sering menentukan pada keputusan yang mereka ambil tentang pengajaran. Diskusi kami terfokus pada pengaruh latar belakang jurusan ilmu atas pengajaran sejarah Amerika."

\section{KESIMPULAN}

Hasil keseluruhan penelitian ini dapat disimpulkan bahwa, pada pelaksanaan teknik evaluasi pembelajaran Sejarah Peradaban Islam (SPI) di IAIN Sultan Maulana Hasanuddin Banten masih berorientasi pada hasil belajar, belum berorientasi pada proses. Dosen dominan memilih teknik evaluasi dengan teknik tes yang mengedepankan ranah kognitif. Ranah ini mengedepankan pengetahuan dengan level yang rendah. Tidak sesuai dengan tujuan pembelajaran Sejarah Peradaban Islam yang berupa pemikiran kritis dan memiliki kepribadian Islam. 
Pola teknik evaluasi yang digunakan dosen mata Kuliah Sejarah Peradaban Islam, yaitu kehadiran di kelas, partisipasi di dalam kelas, evaluasi tugas mingguan, dan evaluasi keterampilan mahasiswa. Mayoritas dosen lebih siap dengan penilaian tes, dibandingkan untuk penilaian non tes. Relatif kurang beragamnya pelaksanaan teknik evaluasi pembelajaran Sejarah Peradaban Islam oleh dosen, disebabkan oleh dua faktor, yaitu tujuan pembelajaran dan latar belakang pendidikan dosennya. Kedua faktor ini mempengaruhi perencanaan, proses, dan teknik evaluasi pembelajaran Sejarah Peradaban Islam.

\section{DAFTAR PUSTAKA}

[1] Aman, Model Evaluasi Pembelajaran Sejarah (Yogyakarta: Ombak, 2011).

[2] Bloom, Benjamin S. at all. (1956). Taxonomy of Educational Objectives. London: Longman.

[3] Hasan, Hasan (2012). Pendidikan Sejarah Untuk Memperkuat Pendidikan Karakter. Jurnal Paramitha UNES Vol. 22 No. 1-2 Januari 2012), h.124. https://journal.unnes.ac.id. Di akses 17 April 2018

[4] Gronlund, E Norman (1976). Measurement and Evaluation in Teaching, third edition. (Macmillan Publishing Co., Inc, New York, Collier Macmillan Publishers, London.

[5] Phenix, Philip H. (1964). Realms of Meaning: A Philosophy of The Curriculum for General Education. New York: McGraw-Hill Book Company.

[6] Supriatna, Nana (2012), Penggunaan Konsep Ilmu Sosial dan Konstruksi Pembelajaran Sejarah Kritis. (Semarang: UNES Jurnal Paramitha Vol. 22 No. 1-2 Januari 2012), h.124. https://journal.unnes.ac.id. Di akses 17 April 2018 
[7] Winerburg, Sam. (2006). Berpikir Historis. Penerjemah: Masri Maris. Jakarta: Yayasan Obor.

[8] Yatim, Badri. (2010). Sejarah Peradaban Islam. Jakarta: Raja Grafindo Persada. 